\title{
A national survey of screening for congenital dislocation of the hip
}

\author{
Carol Dezateux, Sara Godward
}

\begin{abstract}
Objective-To identify current screening and management practices for congenital dislocation of the hip (CDH), and determine the extent to which ultrasound imaging of the hips is practised throughout the United Kingdom and the Irish Republic.

Methods-Postal questionnaire to paediatricians responsible for the routine neonatal care of infants in all maternity units in the UK and the Irish Republic.

Results-Questionnaires were returned for 254 maternity units $(92 \%$ response rate). By 1994, 69\% of maternity units had access to ultrasound imaging of the hips, compared to $14 \%$ in 1984 . Ultrasound imaging of the hip was not used for universal primary screening, but in $93 \%$ of units was undertaken for further assessment of infants with clinically detected hip instability or those identified as being at high risk of $\mathrm{CDH}$, or both. Clinical screening of newborn infants was performed by junior paediatricians, but training with a 'Baby Hippy' hip simulator model was provided in only $37 \%$ of units. Treatment of clinically detected hip instability, initiated by an orthopaedic surgeon in $93 \%$ of units, varied widely in type and duration.

Conclusions-Ultrasound imaging of the hip is increasingly used in the UK for secondary, rather than primary, screening. Current recommendations are implemented to a variable extent nationally, and the existing wide variation in screening and management for CDH reflects a lack of research evidence to support current screening practices. The effectiveness of screening for $\mathrm{CDH}$ needs to be established.

(Arch Dis Child 1996; 74: 445-448)
\end{abstract}

Keywords: congenital dislocation of the hip, screening, ultrasound imaging of the hips.

A United Kingdom policy of universal screening for congenital dislocation of the hip (CDH) was formally introduced in $1969 .^{1}$ Current guidelines $^{2}$ recommend clinical examination by the Ortolani-Barlow test to detect infants with dislocated or dislocatable hips within 48 hours of birth, at discharge from hospital of birth, and at 6 weeks of age. Without screening, the birth prevalence of established $\mathrm{CDH}$ among northern Europeans is approximately 1 per $1000 .^{3}$ It has been estimated from recent UK figures ${ }^{4}$ that between four and five infants are treated for each child who might otherwise develop CDH. ${ }^{6}$ The extent of false negative and false positive diagnoses varies between UK centres, ${ }^{4}$ 7-10 raising concerns about the reliability of the Ortolani-Barlow test. $^{11} 12$ The effectiveness of the current policy has not been formally evaluated. ${ }^{36} 13-15$ Although universal primary ultrasound screening has been adopted recently in some European countries, ${ }^{1617}$ the reported subsequent increases in treatment and follow up of screened infants ${ }^{161819}$ have tempered enthusiasm for its potential role in the United Kingdom. The value of ultrasound as a secondary screening test is equally uncertain. In 1989, the Department of Health initiated a review of current screening policy. ${ }^{20}$ As part of this review, a national survey was undertaken, under the auspices of the Medical Research Council working party on $\mathrm{CDH}$, to identify current screening and management practices for hip instability, and to determine the extent to which ultrasound imaging of the hip is practised in the United Kingdom and the Irish Republic.

\section{Methods}

In December 1993, a questionnaire requesting information on screening and management practices for $\mathrm{CDH}$ was sent to paediatricians responsible for the routine neonatal care of infants in each maternity unit in the United Kingdom and the Irish Republic. Paediatricians and maternity units were identified from the Directory of Emergency and Special Care Baby Units (SCBUs), the Medical Directory, the Health Services Year Book, and a list of SCBUs in England and Wales compiled by the Neonatal Nurses' Association. A single paediatrician was contacted in each unit and non-respondents were sent two further questionnaires at six week intervals. Respondents were asked to list all the maternity units for which they provided neonatal cover, to state the number of deliveries for 1993 in each unit, and to confirm whether the practices described applied to all units for which they were responsible. When practices differed between units covered by a single respondent, information for these units was obtained separately. If necessary, a consultant radiologist or an orthopaedic surgeon nominated by the responding paediatrician provided further details.

\section{Results}

Paediatricians returned questionnaires for 254 $(92 \%)$ of the 277 maternity units identified, representing $93 \%$ of births in the United

\section{Correspondence to: Accepted 21 January 1996 \\ Epidemiology and of Child Health London WC1N 1EH C Dezateux




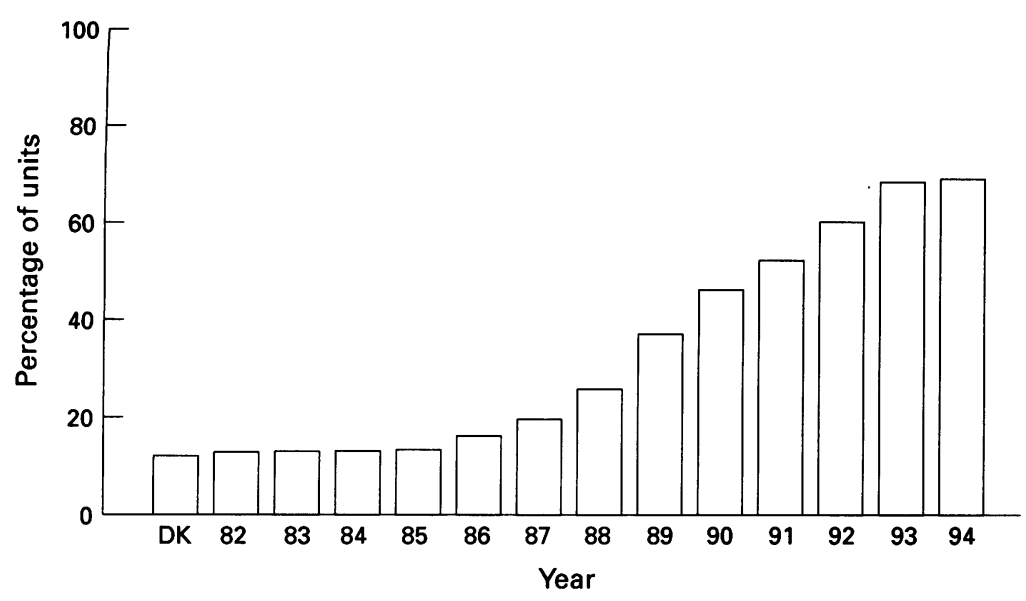

Cumulative percentage of maternity units with access to ultrasound imaging of the hip by first year of access. $D K=$ 'don't know', that is, respondent unable to identify year.

Kingdom and the Irish republic in 1992. The median (range) annual deliveries of units responding was 2800 (100 to 7000 ).

The first screening examination was routinely offered within 24 hours of birth, as recommended, in only $69 \%$ of units, but in all units within 48 hours. In $30 \%$ of units, a second routine screening test was never undertaken before discharge; age at discharge was the determining factor, and only 21 units (8\%) attempted a second examination in all infants. A paediatric senior house officer was responsible for routine screening before discharge, either alone (182 units; $72 \%$ ), or together with other junior paediatric and obstetric staff (62 units; 24\%). Formal training with a 'Baby Hippy' hip simulator model was available in 94 units $(37 \%)$.

At the beginning of 1994, 176 units (69\%) had access to ultrasound examination of the hips compared to $14 \%$ in 1984 (figure), and a further $4 \%$ planned to introduce this over the next 12 months. Ultrasound was performed to assess or manage infants with clinically detected hip abnormalities (79 units; $45 \%$ ), to screen infants at high risk of $\mathrm{CDH}$ (11 units; $6 \%$ ), or both (85 units; $48 \%$ ). Only one unit undertook routine universal primary ultrasound screening. Radiologists and radiographers, alone $(71 \%)$ or together with orthopaedic surgeons (16\%), performed and reported the ultrasound examination. The type of examination performed and method of reporting varied between units, with $39(22 \%)$ performing a static examination, 60 (34\%) a dynamic examination, and $67(38 \%)$ a combination of both.

While 159 units (63\%) operated a particular policy for infants considered to be at high risk of $\mathrm{CDH}$, the criteria used to identify such infants varied and included: a family history of $\mathrm{CDH}(100 \%)$, breech presentation (84\%), talipes $(66 \%)$, presence of other congenital abnormalities (42\%), oligohydramnios $(31 \%)$, and family history of clicking hips (16\%). Infants with some or all of these risk factors were further assessed with ultrasound ( 85 units; $53 \%$ ) and/or repeat clinical examination at a later age (125 units; $79 \%$ ).

Infants in whom a dislocated or dislocatable hip was suspected before discharge were treated immediately in one third and one quarter of units respectively. Orthopaedic surgeons were primarily responsible for making the decision to start treatment (237 units; 93\%), but this varied in type and proposed duration. Dislocated or dislocatable hips were treated with a splint appliance in 226 units $(89 \%)$. A Pavlik harness or von Rosen splint was most frequently used to treat dislocated hips (32\% and $15 \%$ of units respectively) and dislocatable hips (31\% and $12 \%$ of units respectively). Proposed duration of treatment ranged from two to 52 weeks, but was less than 12 weeks in $70 \%$ of units. Personnel responsible for fitting splint appliances included orthopaedic surgeons, physiotherapists, orthopaedic nurses, orthotists, plaster room technicians, and appliance officers.

Only $40 \%$ of respondents were able to identify an individual in their district responsible for keeping the screening programme under review and this person was usually a consultant orthopaedic surgeon or paediatrician.

\section{Discussion}

This survey has revealed that, over the last decade, there has been a fivefold increase in the number of units in the United Kingdom and the Irish Republic using ultrasound imaging of the hip. Ultrasound is used to assess and manage infants with clinically detected hip instability and those at high risk of $\mathrm{CDH}$, rather than for primary screening. Its use as a basis for deciding which infants with clinically detected hip instability require abduction splinting may reduce unnecessary treatment. Abduction splinting is not without hazard 2122 as avascular necrosis of the contralateral hip, ${ }^{23}$ pressure sores, ${ }^{24}$ and nerve palsies ${ }^{25}$ have been reported in treated infants. Unnecessary treatment may, in addition, have financial and other implications for infants and their families, as well as for the health service. While the use of ultrasound as a secondary screening test may reduce the false positives associated with primary clinical screening, the cost-effectiveness of this policy has not been evaluated. One controlled trial reported a $71 \%$ reduction in treatment among infants with clinical hip instability allocated, on an alternate basis, to ultrasound, compared to those allocated immediate treatment, ${ }^{26}$ but was too small to assess reliably the outcome for those left untreated. ${ }^{20}$ The effectiveness of selective ultrasound screening of infants considered to be at high risk of $\mathrm{CDH}$ is equally uncertain, although in one study the incidence of late presenting $\mathrm{CDH}$ was not reduced following its introduction. ${ }^{27}$

There is limited consensus nationally in relation to the performance and reporting of ultrasound examination of the hip. While static ultrasound examination is used in a number of European countries, ${ }^{16} 17$ and dynamic examination in North America, ${ }^{18}$ the findings of this survey indicate that both methods are performed in the United Kingdom, either alone or in combination. Although the performance of these two techniques has been compared, ${ }^{28}$ the 
effectiveness of either in predicting which infants are destined to develop $\mathrm{CDH}$ remains unclear, ${ }^{18}$ and even experienced examiners may differ widely in their performance and interpretation of ultrasound images. ${ }^{29} 30$

Screening for $\mathrm{CDH}$ is a multidisciplinary service, involving paediatricians, radiologists, and orthopaedic surgeons. At present, it is mainly junior paediatricians who carry out the first and second screening examinations, and general practitioners the examination at six weeks. The second examination may reveal previously unsuspected hip instability but, with trends to earlier discharge, is either not attempted in hospital, or is performed within a few days rather than within one week of the first examination. ${ }^{31}$ Coverage may be further reduced, or come increasingly within the domain of primary care, as a consequence of recent changes in maternity services. ${ }^{32}$ Formal training, as recommended by current guidelines, was available in only $37 \%$ of maternity units. There are advocates for specifically trained personnel, such as physiotherapists, 58 dedicated to hip screening. ${ }^{33}$ In contrast to other national screening programmes, an infrastructure is lacking to provide training in clinical examination and to define and monitor standards. However, such standards may be difficult to define as even experienced examiners may differ considerably in the criteria used to determine an acceptable OrtolaniBarlow test, ${ }^{12}$ or in its interpretation. ${ }^{34}$

The timing, nature, and duration of treatment of infants with hip instability varies widely in the United Kingdom. There have been no randomised trials of different treatment regimens, although the effectiveness of early non-surgical treatment is central to the rationale for screening. While only a small proportion of infants initially treated with a splint appliance appear to require subsequent surgery, ${ }^{20}$ recent data from two centres in the in the United Kingdom suggest that almost half of those requiring surgery for $\mathrm{CDH}$ are failures of early non-surgical treatment rather than failures of detection. ${ }^{4}$ The proportion of infants eventually treated is strongly influenced by the age at which diagnosis is confirmed and treatment started, as hip instability, when detected within the first days of life, usually resolves spontaneously. ${ }^{35-37}$

The failure to implement current recommendation $s^{2}$ for keeping the hip screening programme under review was documented previously by Jones et al in 1991,38 and the findings of this survey suggest little improvement since then. This may reflect uncertainty as to how outcome should be assessed and the value of monitoring the programme within districts, where small numbers may preclude meaningful interpretation. An infrastructure to support a national audit is lacking. ${ }^{39-41}$

The need for a formal evaluation of the costeffectiveness of both current and alternative methods of screening for $\mathrm{CDH}$ is increasingly recognised. 62042 The emergence of hip ultrasound has renewed the impetus to evaluate current practices. In the United Kingdom, ultrasound is principally used as a secondary screening test and, although widespread, an opportunity to evaluate this practice remains. In January 1994, recruitment started to a MRC funded multicentre randomised trial to assess the cost-effectiveness of ultrasound in the management of infants with clinically detected hip instability. It is being coordinated by the Perinatal Trials Service in Oxford.

While evaluation of primary screening for $\mathrm{CDH}$ should ideally include assessment of current, as well as alternative, screening methods, screening by the Ortolani-Barlow test has formed an established part of paediatric practice for more than a quarter of a century. This may have implications for the feasibility, acceptability, and medico-legal aspects of a trial of primary screening. Whatever the shape of future screening services, outcome measures and information systems are required to support routine monitoring of $\mathrm{CDH}$. The challenge remains to develop a more scientific basis for screening services aimed at improving the outcome of this important and disabling childhood condition.

The support of the paediatricians, orthopaedic surgeons and radiologists, who gave time to complete the survey questionnaires, and the British Paediatric Association Surveillance Unit, the British Orthopaedic Association and members of the MRC Working Party is gratefully acknowledged. This work was Working Party is gratefully acknowledged. This work was
supported by a grant from the Medical Research Council. CD supported by a grant from the Medical
is supported by the Wellcome Trust.

1 Standing Medical Advisory Committee. Screening for the detection of congenital dislocation of the hip in infants. London: Department of Health and Social Security, 1969.

2 Standing Medical Advisory Committee and the Standing Nursing and Midwifery Advisory Committee. Screening for the detection of congenital dislocation of the hip. London: the detection of congenital dislocation of the hip. Lon
Department of Health and Social Security, 1986.

3 Leck I. An epidemiological assessment of neonatal screening for dislocation of the hip. $\exists R$ Coll Physicians 1986; 20: 56-62.

4 Boeree NR, Clarke NMP. Ultrasound imaging and secondary screening for congenital dislocation of the hip. $\mathcal{F}$ Bone $\mathcal{F o i n t}$ Surg (Br) 1994; 76-B: 525-33.

5 Fiddian NJ, Gardiner JC. Screening for congenital dislocation of the hip by physiotherapists. Results of a ten year study. f Bone foint Surg $(\mathrm{Br})$ 1994; 76-B: 458-9.

6 Screening Brief: Congenital dislocation of the hip. 7 Med Screening 1995; 2: 117.

7 Lennox IAC, McLauchlan J, Murali R. Failures of screening and management of congenital dislocation of the hip. and management of congenital dislocation

8 Krikler SJ, Dwyer NSP. Comparison of results of two approaches to hip screening in infants. $\mathcal{F}$ Bone foint Surg Br) 1992; 74-B: 701-3.

9 Dunn PM, Evans RE, Thearle MJ, Griffiths HED, Witherow PJ. Congenital dislocation of the hip: early and late diagnosis and management compared. Arch Dis Child 1985; 60: 407-14.

10 Patterson CC, Kernohan WG, Mollan RAB, Haugh PE, Trainor BP. High incidence of congenital dislocation of the hip in Northern Ireland. Paediatr Perinat Epidemiol 1995; 9: 90-7.

11 Roberton NRC. Screening for congenital hip dislocation. Lancet 1984; i: 909-10.

12 El-Shazly M, Trainor B, Kernohan WG, et al. Reliability of the Barlow and Ortolani tests for neonatal hip instability. f Med Screening 1994; 1: 165-8.

13 Parkin DM. How successful is screening for congenital disease of the hip? Am $\mathcal{F}$ Public Health 1981; 71: 1378-83.

14 Bennet GC. Screening for congenital dislocation of the hip. f Bone foint Surg (Br) 1992; 74-B: 643-4.

15 Watson JAS. Screening for congenital dislocation of the hip. Matern Child Health 1990; 15: 310-14.

16 Tonnis D, Storch K, Ulbrich H. Results of newborn screening for $\mathrm{CDH}$ with and without sonography and correlation of risk factors. 7 Pediatr Orthop 1990; 10 145-52.

17 Graf R, Tschauner C, Klapsch W. Progress in prevention of late developmental dislocation of the hip by sonographic newborn hip 'screening': results of a comparative follownewborn hip 'screening': results of a compara

18 Harcke HT. The role of ultrasound in diagnosis and management of developmental dysplasia of the hip. Pediatr Radiol 1995; 25: 225-7.

19 Rosendahl K, Markestad T, Lie RT. Ultrasound screening for developmental dysplasia of the hip in the neonate: the effect on treatment rate and prevalence of late cases. Pediatrics 1994; 94: 47-52. 
20 Dezateux C, Godward S. Evaluating the national screening programme for congenital dislocation of the hip. $\mathcal{F}$ Med Screening 1995; 2: 200-6.

21 Bradley J, Wetherill M, Benson MKD. Splintage for congenital dislocation of the hip. $f$ Bone foint Surg (Br) 1987; 69-B: 257-63.

22 Iwasaki $K$. Treatment of congenital dislocation of the hip by the Pavlik harness. $\mathcal{f}$ Bone foint Surg (Am) 1983; 65-A: $760-7$.

23 Gore DG. Iatrogenic avascular necrosis of the hip in young hildren. F Bone foint Surg (Am) 1974; 56-A: 493-502

24 Langkamer VG, Clarke NMP, Witherow P. Complications of splintage in congenital dislocation of the hip. Arch Dis Child 1991; 66: 1322-5.

25 Mubarak S, Garfin S, Vance R, McKinnon B, Sutherland D. Pitfalls in the use of the Pavlik harness for treatment of congenital dysplasia, subluxation, and dislocation of the hip. F Bone foint Surg ( $\mathrm{Am})$ 1981; 63-A: 1239-48.

26 Gardiner HM, Dunn PM. Controlled trial of immediate splinting versus ultrasonographic surveillance in congenitally dislocatable hips. Lancet 1990; ii: 1553-6.

27 Clarke NMP, Clegg J, Al-Chalabi AN. Ultrasound screening of hips at high risk for $\mathrm{CDH}$ : failure to reduce the inciof hips at high risk for CDH: failure to reduce the inci-
dence of late cases. $\mathcal{f}$ Bone foint Surg $(\mathrm{Br})$ 1989; 71-B: dence

28 Engesaeter LB, Wilson DJ, Nag D, Benson MKD. Ultrasound and congenital dislocation of the hip. The importance of dynamic assessment. $\mathscr{f}$ Bone foint Surg $(\mathrm{Br})$ 1990; 72-B: 197-201.

29 Dias JJ, Thomas IH, Lamont AC, Mody BS, Thompson JR The reliability of ultrasonographic assessment of neonatal hips. $\mathcal{F}$ Bone foint Surg (Br) 1993; 75-B: 479-82.

30 Rosendahl K, Aslaksen A, Lie RT, Markestad T. Reliability of ultrasound in the early diagnosis of developmental dysplasia of the hip. Pediatr Radiol 1995; 25: 219-24.

31 Cartlidge PHT. Routine discharge examination of babies: is it necessary? Arch Dis Child 1992; 67: 1421-2.

32 Court $S$. Examination of the newborn - for what and by whom? Changing Childbirth 1995; 3: 3.

33 Bernard AA, O'Hara JN, Bazin S, Humby B, Jarrett R, Dwyer NSP. An improved screening system for the early detection of congenital dislocation of the hip. $f$ Pediatr Orthop 1987; 7: 277-82.

34 Bialik V, Fishman J, Katzir J, Zeltzer M. Clinical assessment of hip instability in the newborn by an orthopedic surgeon and a pediatrician. 7 Pediatr Orthop 1986; 6: 703-5.

35 Palmen K. Prevention of congenital dislocation of the hip: the Swedish experience of neonatal treatment of hip joint instability. Acta Orthop Scand 1984; 55 (suppl): 1-107.

36 Sanfridson J, Redlund-Johnell I, Uden A. Why is congenital dislocation of the hip still missed? Acta Orthop Scand 1991; 62: 87-91.

37 Barlow TG. Early diagnosis and treatment of congenital dislocation of the hip. F Bone Foint Surg (Br) 1962; 44-B: 292-301.

38 Jones DA, Beynon D, Littlepage BNC. Audit of an official recommendation on screening for congenital dislocation of the hip. $B M \mathcal{F}$ 1991; 302: 1435-6.

39 Knox EG, Armstrong EH, Lancashire RJ. Effectiveness of screening for congenital dislocation of the hip. $\mathcal{F}$ Epidemiol Community Health 1987; 41: 283-9.

40 Macfarlane A. Screening for congenital dislocation of the hip. $B M \mathcal{F}$ 1987; 294: 1047.

41 Macfarlane A. Congenital dislocation of the hip - an epidemiological conundrum. $f$ Matern Child Health 1980;13-15.

42 Screening for congenital hip dysplasia. Lancet 1991; 337: 947-8. 